\title{
The Relationship between Employees' Belief in a Just World and Sustainable Organizational Citizenship Behaviors in Chinese Enterprises: The Moderating Effect Model of Interpersonal Intelligence
}

\author{
Liangli Han ${ }^{1}$, Houyu Zhou ${ }^{1 *}$, and Chunjie Wang ${ }^{2}$ \\ 1 Jing Hengyi School of Education, Hangzhou Normal University, Hangzhou 311121, China; \\ 2020112004061@stu.hznu.edu.cn \\ 2 School of Basic Medical Sciences, Hangzhou Normal University, Hangzhou 311121, China; \\ cjwang@hznu.edu.cn \\ * Correspondence: zhouhouyu1@hznu.edu.cn
}

\begin{abstract}
To both survive and develop continuously, enterprises must overcome many kinds of competition and challenges. Cultivating employees' active and sustainable organizational citizenship behavior is important for enterprises to successfully cope with turbulence and uncertain events during their development. In this study, we investigated the development level of and factors influencing employees' organizational citizenship behavior in current organizations. By using the Belief in a Just World Scale, Organizational Citizenship Behavior Scale, and Interpersonal Intelligence Scale, we investigated 230 employees from 15 different enterprises. The results showed that belief in a just world, interpersonal intelligence, and organizational citizenship behavior were significantly positively correlated. Interpersonal intelligence played a moderating role between belief in a just world and organizational citizenship behavior; the organizational citizenship behavior of individuals with high interpersonal intelligence increased with the strengthening of the belief in a just world, and this increase was larger than that experienced by individuals with low interpersonal intelligence. This meant that under a certain level of belief in a just world, a high level of interpersonal intelligence was more conducive to promoting employees' sustainable organizational citizenship behavior.
\end{abstract}

Keywords: belief in a just world; organizational citizenship behavior; interpersonal intelligence; moderating effect model

\section{Introduction}

With the advent of the intelligent era, economic globalization and market competition are increasingly intensifying. In order to survive and develop in such a complex and changing market environment, organizations should improve their flexibility and innovation ability, which require their employees to assume more responsibility beyond their duties, take more initiative, perform adaptive and innovative behaviors, and contribute wisdom and strength to the organization. Organizational citizenship behavior (OCB) has attracted increased attention from managers and researchers because it can improve organizational efficiency, help the organization to adapt to changing competitive market environments, and strengthen self-management and other emerging management methods.

\subsection{Organizational Citizenship Behavior}

Organizational citizenship behaviors are important to the sustainable development of enterprises. The concept of OCB was formally proposed by Organ and Dennis [1]. Organizational citizenship behavior is the spontaneous behavior of employees rather than one defined by the normal work-performance-based salary system. However, such 
behavior can promote organizational work performance by maintaining and improving an organizational environment that is conducive to work performance. Different from work-specific in-role behaviors, organizational citizenship behavior is extra-role behavior that includes cooperating with others, volunteering to undertake additional tasks, helping others finish their work, volunteering to perform duties beyond the work requirements, and other behaviors [2]. Good organizational citizenship behavior features altruism (e.g., taking the initiative to help others handle tasks or issues related to the organization), a sense of responsibility (e.g., performing duties far beyond the work requirements), courtesy (e.g., giving advance notice, reminding, and consulting), a sportsperson-like spirit (e.g., avoiding complaints or grievances), and civic virtue (e.g., actively participating in the organization's governance and providing appropriate feedback) $[3,4,5]$. All these behaviors serve as a prerequisite to continuously ensure the effective operation of an organization. Therefore, sustainable organizational citizenship behaviors are crucial for enterprises to gain competitive advantages.

Walz and Podsakoff found that the average level of employees' organizational citizenship behaviors is positively correlated with organizational performance and workgroup performance [6, 7]. That is, the higher the level of employees' organizational citizenship behaviors, the more the organizational and workgroup performances improve. Additionally, some studies discovered that employees with positive emotions are more willing to engage in organizational citizenship behaviors [8,9], and employees can participate in such behaviors to enhance their image in the organization. In recent years, the number of studies on organizational citizenship behaviors has increased, and such behaviors also attracted the attention of many managers. These behaviors can create and maintain the organizational environment, improve the effectiveness and smooth operation of the organization as a whole, and play a vital role in the development of enterprises.

\subsection{Belief in a Just World}

Scholars generally think that workplace justice, fairness, or the concept of fairness serve as key factors that affect employees' work attitudes and work behaviors [10, 11, 12, 13]. The belief in a just world as a common concept of fairness held by employees is a psychological demand, belief, and pursuit of justice for individuals; that is, individuals believe that they live in a just world, that the world is equitable and harmonious, and that they will receive what they deserve through continuous effort [14]. This belief in a just world can be regarded as a difference in characteristics between individuals [15]. As a basic model, the belief in a just world enables people to steadily face the external environment, and influences the processing, coding, and recalling of people's daily experiences [16]. It plays a pivotal role in individual adaptation to complex physical and social environments. Specifically, the belief in a just world can be divided into general and personal just-world beliefs. The general just-world belief refers to the belief that the world is typically a just place, namely, others are treated fairly; the personal just-world belief is the belief that yourself are treated fairly [17].

The belief in a just world means employees regard their world as fair and meaningful, which cultivates their positive outlook for the future and expectation of their life experience, hence effectively promoting employees' positive behaviors [18]. Research showed that an individual's belief in a just world has a positive impact on altruistic, prosocial behaviors, and other-helping behaviors. Zuckerman discovered a positive correlation between the belief in a just world and altruistic behaviors through experimental research [19]. The results demonstrated that individuals with a strong belief in a just world were more willing to offer assistance than those with a weak belief in a just world. Depalma et al. also found that individuals with a strong belief in a just world were more willing to help those groups that were treated unfairly and exhibited more helping behaviors [20]. Otto and Schmidt pointed out that employees with a strong belief in a just world displayed higher job satisfaction and organizational loyalty, and were more willing to demonstrate organizational citizenship behaviors [21]. Laurin et al. reported that for groups in unfavorable social situations, the stronger the belief in a just world, the 
more willing they were to devote their energy and time to long-term work and careers, and the more resilient they were in the face of difficulties [22].

Previous studies verified that employees' views on organizational justice exert a strong impact on organizational citizenship behaviors [23, 24] because perceived justice promotes trust in non-contractual communication between employees and organizations [25]. Moorman confirmed a positive correlation between the sense of fairness and organizational citizenship behaviors [26]. The results showed that compared to employees with a weak sense of fairness, those who have a strong sense of organizational fairness demonstrate a positive work attitude and perform extra-role behaviors to repay the organization after fulfilling their duties. In addition, Niehaff and Mooman stated that when employees feel that organizational care and distribution are unfair, their discontent will be balanced by reducing personal input, but they will not directly reduce work input to achieve a sense of balance in their mind since reducing such input can directly affect their job performance and remuneration [27]. Instead, organizational citizenship behaviors with hidden characteristics are used to reduce input, thus eliminating employees' sense of unfairness. To summarize, some connections must exist between belief in a just world and organizational citizenship behaviors, which deserves further exploration.

\subsection{Interpersonal intelligence}

The belief in a just world is the motive for individuals to pursue long-term goals and follow social norms. It has an important adaptive function since it enables people to better adapt to their material and social environment; to believe that the environment is stable, fair, and organized [28]; and to proactively perform positive behaviors. In this process, interpersonal intelligence plays an important role. It is an integral part of multiple intelligences related to responding to and understanding information, as well as establishing social contact and interaction with others [29]. Gardner explained that interpersonal intelligence is the ability to understand and create differences and respond effectively to various interpersonal cues, including social sensitivity, social insights, social communication, and altruistic behaviors [30]. Employees with high interpersonal intelligence can be leaders among their peers and encourage people to work together to create a sense of belonging; they typically have rich common sense, superb social skills, and the ability to make friends in various social groups; and they are more willing to work collectively and show high working efficiency [31]. Therefore, good interpersonal intelligence can effectively improve the interpersonal atmosphere of organizations or groups, help individuals to communicate and cooperate voluntarily, eliminate contradictions, enhance cohesion, and thus increase individuals' helping behaviors. For instance, Fitri studied the correlation between the interpersonal intelligence and prosocial behaviors of primary school students; they found a significant positive correlation between the two variables, and that children with high interpersonal intelligence were more inclined to show behaviors of helping others [32]. Cirelli clarified that high interpersonal intelligence promoted individuals' prosocial behaviors and increased the frequency of prosocial behaviors [33]. These studies' findings indicated that interpersonal intelligence is significantly related to positive behaviors and that by improving interpersonal intelligence, employees can get along with colleagues, superiors, and subordinates; cooperate better with others; and are more willing to perform some extra-role behaviors that are beneficial to organizational development.

1.4. The Moderating Role of Interpersonal intelligence in the Relationship between Belief in a just world and Organizational citizenship behavior

Organizational citizenship behaviors can promote employees' professionalism, enhance productivity, create a better working environment, and benefit organizations in many other ways [34]. Therefore, the study of organizational citizenship behaviors is important for the development and growth of enterprises. As a concept of fairness, the belief in a just world encourages employees to regard their world as fair, to build trust in others and social institutions, and to perceive the significance of events in life to maintain a positive working attitude and promote positive behaviors in employees [35]. 
Interpersonal intelligence is the ability to understand and create differences and respond effectively to various interpersonal cues, including social sensitivity, social insights, social communication, and altruistic behaviors. Previous theoretical and empirical studies found that individuals with low interpersonal intelligence have few friends in various social groups and prefer to study or work alone. They are indifferent to other people's affairs, tend to care more about personal interests than collective benefits, and often do not perform actions for tasks beyond their own responsibilities. This problem urged us to explore the regulating role of interpersonal intelligence. Therefore, in this study, we aimed to explore the relationship between employees' just-world beliefs and organizational citizenship behaviors, and the moderating effect of interpersonal intelligence between them.

Our main hypotheses were as follows:

Hypothesis 1: The correlation between the belief in a just world and organizational citizenship behaviors is positive and significant.

Hypothesis 2: The correlation between the belief in a just world and interpersonal intelligence is positive and significant.

Hypothesis 3: The correlation between interpersonal intelligence and organizational citizenship behaviors is positive and significant.

Hypothesis 4: Interpersonal intelligence plays a moderating role between belief in a just world and organizational citizenship behaviors.

\section{Method}

\subsection{Participants}

A convenient sample of 230 employees was drawn from 15 different companies in Hangzhou, Sichuan, and Guizhou, China. Questionnaires were distributed to them and 193 valid questionnaires (114 men and 79 women) were returned. Among them, 25\% of employees were 25 years old and below, 61\% were $26-35$ years old, $9 \%$ were $36-45$ years old, and $5 \%$ were 46 years old and above. In terms of education level, those with high school education and below accounted for $11.4 \%$, those with a college degree accounted for $23.3 \%$, those with a bachelor's degree accounted for $53.9 \%$, and those with a graduate degree or above accounted for $11.4 \%$ of the sample.

\subsection{Measures}

We used an empirical research method, namely, a questionnaire survey, in this study. The content of the questionnaire included questions regarding belief in a just world, organizational citizenship behavior, and interpersonal intelligence. All instruments were psychometrically sound, as evidenced by the sufficient reliabilities of the scales used in the current study. A self-constructed demographic survey was used to obtain information about participants, including sex, age, marital status, educational level, working years, and rank.

\subsubsection{Belief in a Just World Scale}

The Belief in a Just World Scale, which consists of 13 items, is used to measure an individual's perceptions of fairness [36]. The scale is based on the BJW scale compiled by Dalbert [37], and it has good reliability and validity among Chinese college students. It includes the General Just-World Belief subscale and the Personal Just-World Belief subscale, in which items 1-6 consider the dimensions of general just-world belief and items 7-13 are the dimensions of personal just-world belief. Each question has a 7-option rating scale ranging from strongly disagree 1 to completely agree 7 . Higher scores indicate higher levels of belief in a just world. The internal consistency of the scale is satisfactory $(\alpha=0.932)$.

\subsubsection{Organizational Citizenship Behavior Scale}

Podsakoff et al. constructed the Organizational Citizenship Behavior Scale in 1997 [38]. It consists of 10 items, including two dimensions of helping behavior and civic virtue, among which, items 1-7 are the dimensions of helping behavior and items 8-10 are the dimensions of civic virtue. The scale has a seven-point rating scale ranging from 
strongly disagree 1 to completely agree 7 . After summing the overall answers, a higher score represents more willingness to show organizational citizenship behavior. The internal consistency for the scale is high $(\alpha=0.925)$.

\subsubsection{Interpersonal Intelligence Scale}

In this study, we used the Interpersonal Intelligence Scale to extract some items from the Positive Organizational Behavior Scale revised by $\mathrm{Lu}$ to measure the individual's interpersonal relationships [39], thereby investigating the individual's interpersonal intelligence level. The scale comprises 4 items with a five-point rating scale ranging from completely disagree 1 to completely agree 5 . The higher the score, the higher the individual's interpersonal intelligence level. The scale has sufficient reliability of 0.897 .

\subsection{Procedure}

We obtained permission for data collection from the subjects. The employees were individually contacted and we briefed them about the nature and objectives of the study. They were assured that the information collected would be kept confidential. After that, informed consent was obtained and the above-mentioned questionnaires were distributed. Finally, the participants were acknowledged for their support and cooperation.

\section{Results}

Table 1 presents the means, standard deviations, alpha reliabilities, and ranges of all the scales and subscales used in the study. The results indicated that all scales and subscales achieved a satisfactory alpha level ranging from 0.75 to 0.93 .

Table 1. Descriptive and psychometric properties of scales and subscales of the present study ( $N=$ 193).

\begin{tabular}{cccccc}
\hline Variable & Items & M & SD & $\boldsymbol{\alpha}$ & Range \\
\hline General Just-World Belief & 6 & 26.41 & 7.79 & 0.87 & $1-7$ \\
Personal Just-World Belief & 7 & 33.25 & 8.19 & 0.91 & $1-7$ \\
Belief in a Just World & 13 & 59.67 & 14.92 & 0.93 & $1-7$ \\
$\quad$ Helping Behavior & 7 & 37.98 & 8.00 & 0.93 & $1-7$ \\
$\quad$ Civic Virtue & 3 & 15.15 & 3.56 & 0.75 & $1-7$ \\
Organizational Citizenship & 10 & 53.12 & 10.82 & 0.93 & $1-7$ \\
$\quad$ Behavior & & 16.17 & 2.99 & 0.90 & $1-5$ \\
Interpersonal Intelligence & 4 & & & &
\end{tabular}

Table 2 shows a significant positive relationship between the belief in a just world and organizational citizenship behavior in which the general and personal just-world beliefs were significantly positively correlated with organizational citizenship behavior. The results also revealed a positive correlation between interpersonal intelligence and belief in a just world. Organizational citizenship behavior was positively related to interpersonal intelligence, among which, helping behavior and civic virtue were significantly positively related to interpersonal intelligence. 
Table 2. Correlation matrix for all variables $(N=193)$.

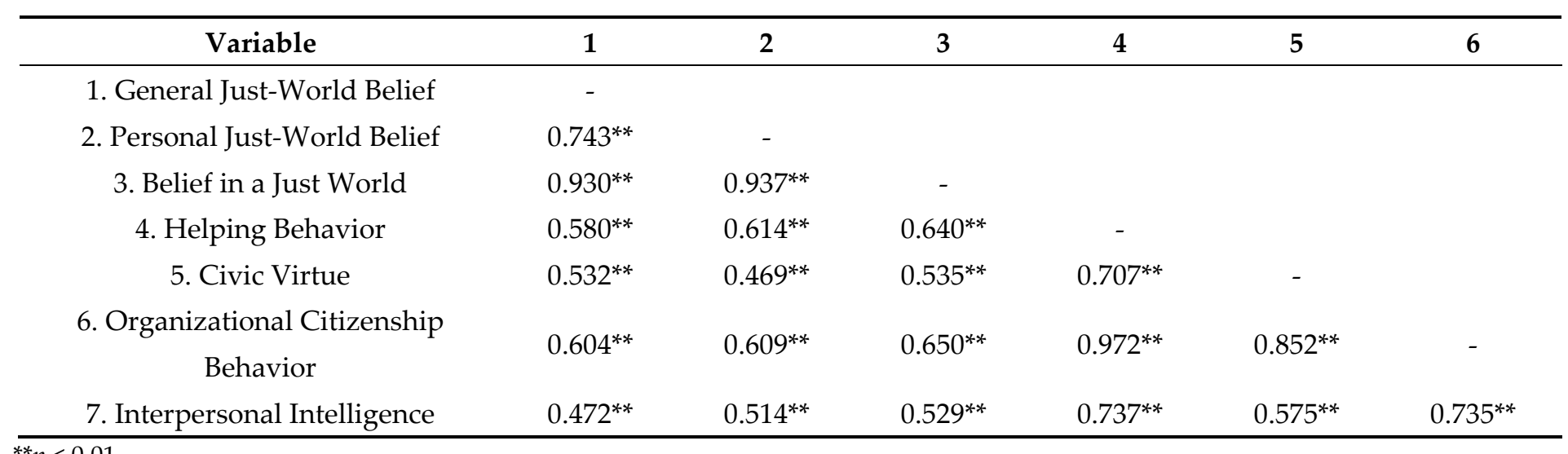

Table 3 shows the hierarchical regression analysis results for predicting organizational citizenship behavior moderated by interpersonal intelligence in relation to belief in a just world. To reduce the multicollinearity problem, interpersonal intelligence, belief in a just world, and their product variables were centrally treated. The first model $(\mathrm{F}=139.48, p<0.001)$ showed that belief in a just world was a positive predictor of organizational citizenship behavior $(\beta=0.612, \mathrm{t}=11.81, p<0.001)$. This model indicated that $41.9 \%$ of the variance in organizational citizenship behavior could be attributed to the belief in a just world $\left(\Delta \mathrm{R}^{2}=0.419, \Delta \mathrm{F}=139.48, p<0.001\right)$. The second model was found to be a significant model $(\mathrm{F}=164.81, p<0.001)$ that was responsible for $21.1 \%$ of the variation in organizational citizenship behavior due to interpersonal intelligence $\left(\Delta R^{2}\right.$ $=0.211, \Delta \mathrm{F}=110.32, p<0.001)$, and interpersonal intelligence had a positive predictive effect on organizational citizenship behavior $(\beta=0.197, \mathrm{t}=10.50, p<0.001)$.

Table 3. Moderating role of interpersonal intelligence in the relationship between belief in a just world and organizational citizenship behavior $(N=193)$.

\begin{tabular}{ccc}
\hline Predictor Variable & Adjust $\mathbf{R}^{2}$ & $\beta$ \\
\hline Step I & $0.419^{* * *}$ & \\
Belief in a just world & & $0.612^{* * *}$ \\
Step II & $0.630^{* * *}$ & \\
Belief in a just world & & $0.342^{* * *}$ \\
Interpersonal intelligence & $0.197^{* * *}$ \\
Step III & $0.640^{*}$ & \\
Belief in a just world & & $0.345^{* * *}$ \\
Interpersonal intelligence & & $0.178^{* * *}$ \\
Belief in a just world $\times$ & & $-0.027^{*}$ \\
interpersonal intelligence & & \\
\hline${ }^{*} p<0.05,{ }^{* *} p<0.001$. & &
\end{tabular}

The third model was the final moderation model, where the product of belief in a just world and interpersonal intelligence was used for investigating the moderating influence of interpersonal intelligence in the relationship between belief in a just world and organizational citizenship behavior. The overall model was significant $(\mathrm{F}=115.00, p$ $<0.001$ ) and showed a significant interactive effect of the belief in a just world and interpersonal intelligence on organizational citizenship behavior $(\beta=-0.027, \mathrm{t}=-2.50, p<$ 0.05). This final model of investigation explained an additional $1 \%$ of the variation in organizational citizenship behavior $\left(\Delta \mathrm{R}^{2}=0.01, \Delta \mathrm{F}=6.27, p<0.05\right)$.

Figure 1 depicts the predicted level of organizational citizenship behavior as an outcome of the level of interpersonal intelligence in employees with strong and weak 
levels of belief in a just world. The slopes for high and low levels of interpersonal intelligence indicate positive moderation between belief in a just world and organizational citizenship behavior. The figure shows that as the level of interpersonal intelligence decreased, the positive predictive effect of belief in a just world on organizational citizenship behavior tended to gradually decrease. In other words, for individuals with high levels of interpersonal intelligence, their organizational citizenship behavior was more susceptible to the influence of their belief in a just world.

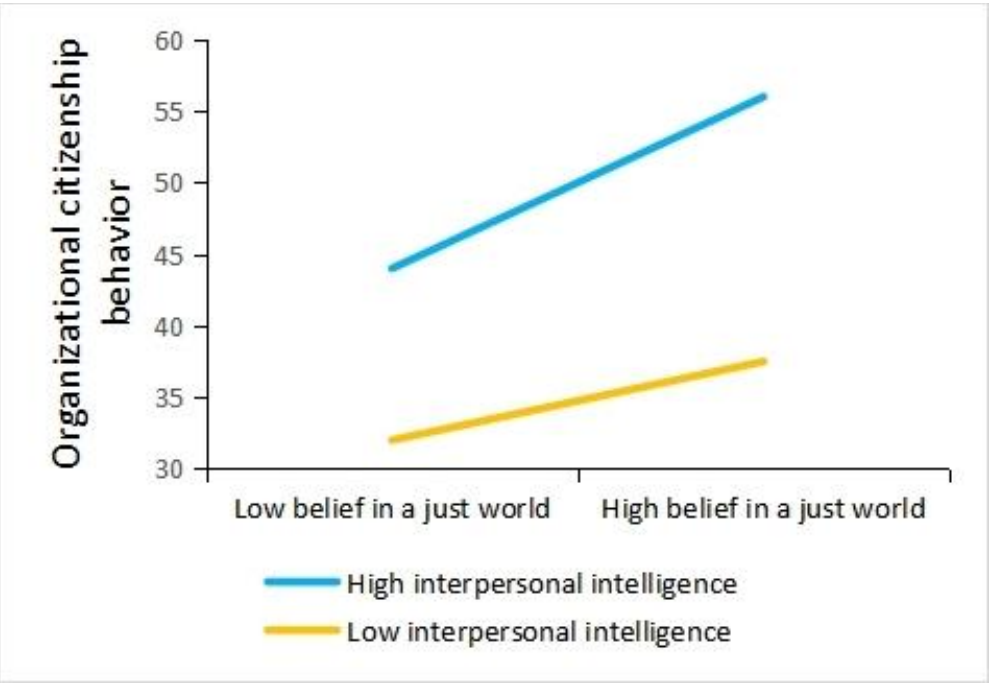

Figure 1. The interactive effect of interpersonal intelligence on the relationship between belief in a just world and organizational citizenship behavior.

Table 4. The moderating role of interpersonal intelligence between personal just-world belief and organizational citizenship behavior $(N=193)$.

\begin{tabular}{ccc}
\hline Predictor Variable & Adjust $\mathbf{R}^{2}$ & $\beta$ \\
\hline Step I & $0.367^{* * *}$ & \\
Personal just-world belief & & $0.563^{* * *}$ \\
Step II & $0.608^{* * *}$ & \\
Personal just-world belief & & $0.290^{* * *}$ \\
Interpersonal intelligence & & $0.208^{* * *}$ \\
Step III & $0.616^{*}$ & \\
Personal just-world belief & & $0.290^{* * *}$ \\
Interpersonal intelligence & & $0.191^{* * *}$ \\
Personal just-world belief & & $-0.025^{*}$ \\
$\times$ interpersonal intelligence & & \\
${ }^{*} p<0.05,{ }^{* *} p<0.001$. & &
\end{tabular}

Table 4 presents the hierarchical regression analysis results for predicting organizational citizenship behavior moderated by interpersonal intelligence in relation to personal just-world belief. The first model $(\mathrm{F}=112.37, p<0.001)$ showed that personal just-world belief was a positive predictor of organizational citizenship behavior ( $\beta=$ $0.563, \mathrm{t}=10.60, p<0.001)$. This model indicated that $36.7 \%$ of the variance could be attributed to personal just-world belief $\left(\Delta \mathrm{R}^{2}=0.367, \Delta \mathrm{F}=112.37, p<0.001\right)$. The second model was also found to be a significant model $(\mathrm{F}=149.88, p<0.001)$, showing positive prediction of interpersonal intelligence in relation to organizational citizenship behavior $(\beta=0.208, t=10.88, p<0.001)$. This model indicated that $24.1 \%$ of the variance could be attributed to interpersonal intelligence $\left(\Delta \mathrm{R}^{2}=0.241, \Delta \mathrm{F}=118.35, p<0.001\right)$. The third model was the final moderation model, where the product of personal just-world belief 
and interpersonal intelligence was entered to investigate the moderating influence of interpersonal intelligence in the relationship between personal just-world belief and organizational citizenship behavior. The overall model was significant $(\mathrm{F}=104.59, p<$ 0.001 ) and showed a significant negative interactive effect of interpersonal intelligence and personal just-world belief on organizational citizenship behavior $(\beta=-0.025, \mathrm{t}=$ $-2.23, p<0.05)$. The final model explained an additional $0.8 \%$ variance in organizational citizenship behavior $\left(\Delta \mathrm{R}^{2}=0.008, \Delta \mathrm{F}=4.98, p<0.05\right)$.

Figure 2 displays the interactive slope for interpersonal intelligence in the relationship with personal just-world belief and organizational citizenship behavior. The slope for high and low levels of interpersonal intelligence indicated positive moderation between personal just-world belief and organizational citizenship behavior. The figure shows that when the level of interpersonal intelligence was low, organizational citizenship behavior was more susceptible to a personal just-world belief, whereas, for individuals with high levels of interpersonal intelligence, personal just-world belief had no significant positive impact on organizational citizenship behavior.

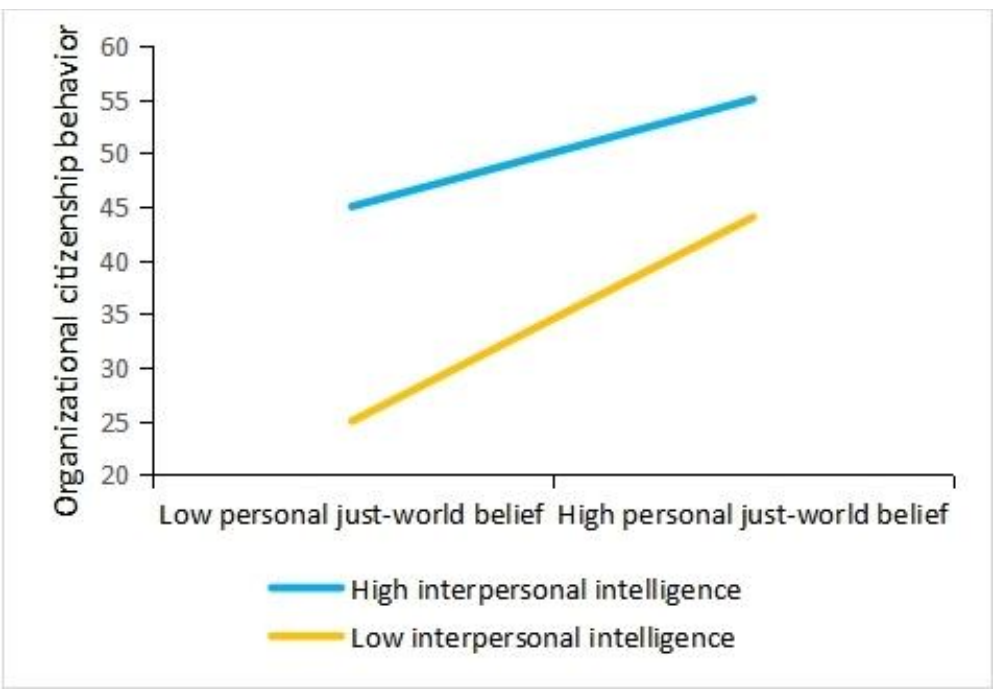

Figure 2. The interactive effect of interpersonal intelligence on personal just-world belief and organizational citizenship behavior.

Table 5 presents the hierarchical regression analysis for predicting organizational citizenship behavior moderated by interpersonal intelligence in relation to general just-world belief. The first model $(\mathrm{F}=109.91, p<0.001)$ showed that a general just-world belief was a positive predictor of organizational citizenship behavior $(\beta=0.503, t=10.48$, $p<0.001)$. This model showed that $36.2 \%$ of the variance could be attributed to general just-world belief $\left(\Delta \mathrm{R}^{2}=0.362, \Delta \mathrm{F}=109.91, p<0.001\right)$.

The second model was also significant $(\mathrm{F}=158.35, p<0.001)$, showing a positive prediction of the effects of interpersonal intelligence on organizational citizenship behavior $(\beta=0.209, \mathrm{t}=11.47, p<0.001)$. This model indicated that $25.9 \%$ of the variance could be attributed to interpersonal intelligence $\left(\Delta \mathrm{R}^{2}=0.259, \Delta \mathrm{F}=131.62, p<0.001\right)$. The third model was the final moderation model, where the product of general just-world belief and interpersonal intelligence was entered for investigating the moderating influence of interpersonal intelligence in the relationship between general just-world belief and organizational citizenship behavior. The overall model was significant $(\mathrm{F}=$ $110.15, p<0.001)$ and showed a significant negative interactive effect of interpersonal intelligence and general just-world belief on organizational citizenship behavior ( $\beta=$ $-0.028, \mathrm{t}=-2.62, p<0.05)$. This final model explained an additional $1.1 \%$ of the variance in organizational citizenship behavior $\left(\Delta \mathrm{R}^{2}=0.011, \Delta \mathrm{F}=6.85, p<0.05\right)$. 
Table 5. The moderating role of interpersonal intelligence between general just-world belief and organizational citizenship behavior $(N=193)$.

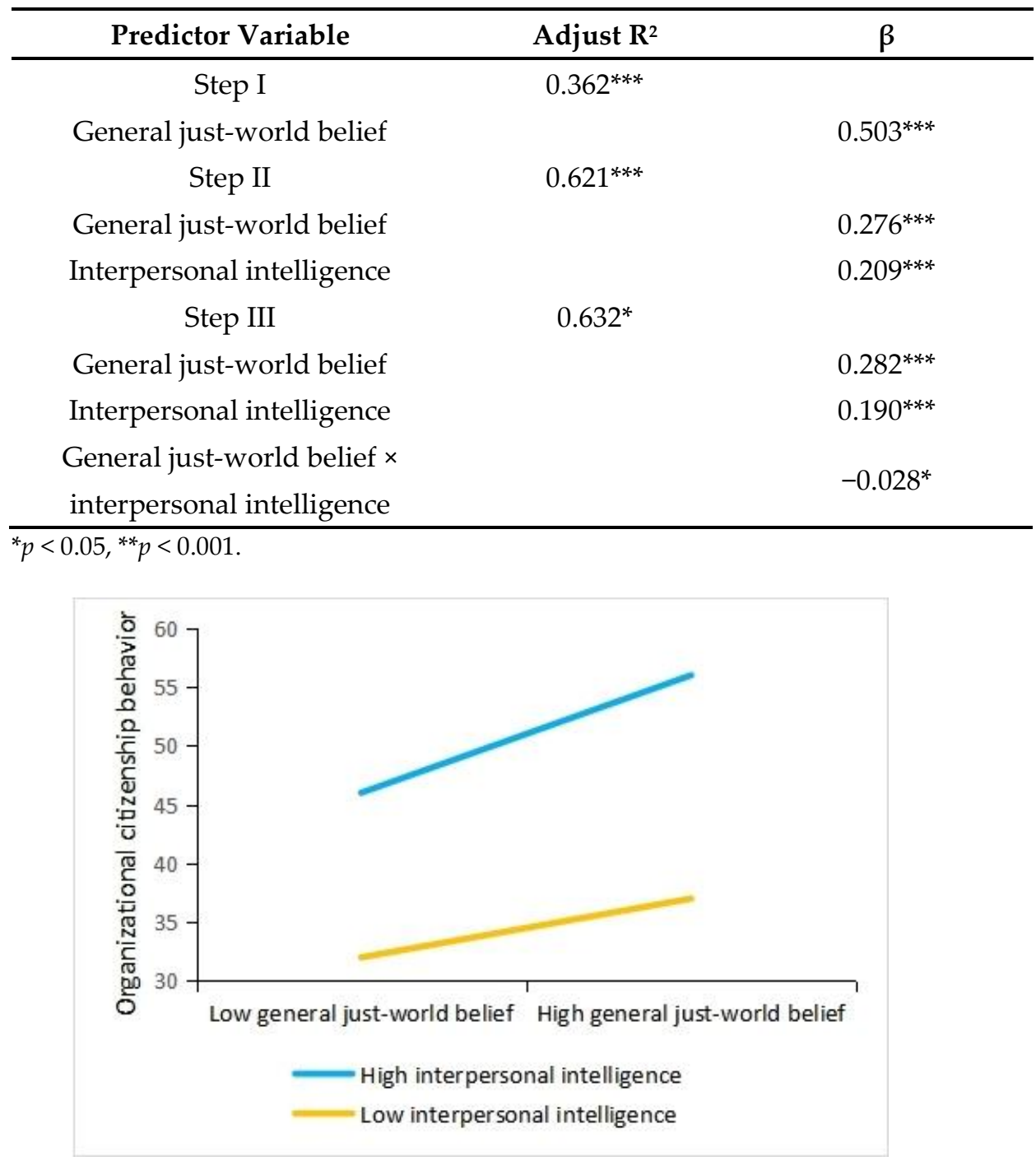

Figure 3. The interactive effect of interpersonal intelligence on general just-world belief and organizational citizenship behavior.

Figure 3 displays the interactive slopes for interpersonal intelligence in relation to general just-world belief and organizational citizenship behavior. The slope for high and low levels of interpersonal intelligence indicates positive moderation between general just-world belief and organizational citizenship behavior. The figure shows that as the level of interpersonal intelligence decreased, the positive predictive effect of general just-world belief on organizational citizenship behavior gradually decreased. In other words, for employees with a high level of interpersonal intelligence, their general just-world belief had a significant positive impact on organizational citizenship behavior, whereas, for employees with a low level of interpersonal intelligence, their general just-world belief had no significant positive impact on organizational citizenship behavior.

\section{Discussion}

In this study, we aimed to explore the relationship between the belief in a just world and organizational citizenship behavior, and the moderating role of interpersonal intelligence between the two variables. Correlation analysis verified the existence of a significant positive correlation between belief in a just world and organizational citizenship behavior. The regression analysis results indicated that belief in a just world 
had a significant positive predictive effect on organizational citizenship behavior, which is consistent with the findings of Farh and Moorman, who reported that fairness indicators can better predict organizational citizenship behaviors, and employees who are treated fairly are more likely to exhibit extra-role behaviors [23, 26]. Moreover, based on social exchange theory, researchers discovered that employees who are well-treated by organizations are rewarded through engaging in organizational citizenship behaviors [27]. In other words, if employees feel they are treated fairly, they may have a positive attitude toward their work, results, and supervisors, and are more willing to exhibit organizational citizenship behaviors. Additionally, previous studies showed that belief in a just world has a significant positive impact on altruistic behaviors and prosocial behaviors [40, 41, 42]. That is, individuals with a strong belief in a just world are more inclined to exhibit prosocial behaviors. As a kind of altruistic helping behavior, organizational citizenship behavior is also influenced by a belief in a just world. These findings provide further support for the results of this study. Individuals with belief in a just world think that the world is fair and everyone's hard work is rewarded accordingly. Thus, they tend to be more willing to exhibit extra-role behaviors that are not required by formal work regulations but are beneficial to the organization and create a working environment that promotes organizational development so that employees can receive more support in their work, cooperate better with colleagues, improve their work quality and efficiency, and receive high-level evaluations from leaders and rewards, such as promotions and salary increases.

We also found a significant positive correlation between the personal and general just-world beliefs and organizational citizenship behaviors; both could positively predict organizational citizenship behavior. Individuals who believe that they are treated fairly or that others are treated fairly have a sense of security. They hold the view that the world is fair and principled, that good acts will be well rewarded, and are more willing to follow social norms. These individuals are more likely to exhibit helping behaviors [43]. However, the positive predictive effect of personal just-world belief on organizational citizenship behavior was stronger than that of general just-world belief on organizational citizenship behavior. People tend to describe themselves as fairer than others. Good self-perception is a part of one's self-concept and positively affects one's behaviors [44]. Personal just-world belief can be interpreted as a personal contract between subjects and the social world in which they live. The more subjects identify with personal just-world belief, the greater the compulsion of the personal contract [35]. Personal contracts importantly regulate the interdependence between subjects and their social world. The more people believe that they are in a just world, the more they feel obligated to act fairly. Therefore, people with strong personal just-world beliefs are more willing to exhibit organizational citizenship behaviors.

The results further indicated that a positive correlation existed between interpersonal intelligence and organizational citizenship behaviors: the former could positively predict the latter. Previous studies did not link interpersonal intelligence with organizational citizenship behaviors, but related studies showed that interpersonal intelligence is positively correlated with prosocial behaviors, and individuals with high interpersonal intelligence are more willing to demonstrate prosocial behaviors [45, 46]. In enterprises, employees with high interpersonal intelligence often communicate and cooperate well with their colleagues, superiors, and subordinates to maintain good interpersonal relationships. Therefore, these employees are more likely to help their colleagues, cooperate with others and provide contributions, and create a harmonious working environment. The results of this study are consistent with the above assumptions.

According to the results of our moderating effect analysis, interpersonal intelligence significantly moderated the relationship between belief in a just world and organizational citizenship behavior. Many researchers reported that maintaining good interpersonal relationships will increase individuals' helping behaviors [47, 48, 49, 50], and individuals with high interpersonal intelligence and a strong belief in a just world 
can use interpersonal intelligence to communicate with their colleagues, superiors, and subordinates at work, thus fostering sound interpersonal relationships. Therefore, individuals with a strong belief in a just world and high interpersonal intelligence tend to have sound interpersonal relationships; can get along well with their colleagues, superiors, and subordinates; and cooperate better with others. They are more willing to demonstrate some extra-role behaviors that are conducive to organizational development. Although individuals with low interpersonal intelligence maintain a strong belief in a just world, they often feel that their work is thankless because they are not good at communicating with others and cannot maintain good interpersonal relationships, which reduces their willingness to show organizational citizenship behaviors. As a result, a decrease in interpersonal intelligence will erode the positive impact of a just-world belief on organizational citizenship behaviors.

Further analysis indicated that interpersonal intelligence had a moderating effect on the relationship between personal just-world belief and organizational citizenship behaviors, and the relationship between general just-world belief and organizational citizenship behaviors. The organizational citizenship behaviors of employees with low interpersonal intelligence were more susceptible to the influence of personal just-world belief. Individuals with low interpersonal intelligence cannot clearly perceive, experience, or predict whether others are treated fairly. However, they have experience and confidence in whether they are treated fairly. They can consider others from their own point of view. Therefore, when they have a strong personal just-world belief, that is, they believe that what they have encountered is fair, they will hold the view that others deserve to be treated fairly as well as themselves. Accordingly, these individuals tend to show kindness to others and are more willing to exhibit organizational citizenship behaviors. For employees with high interpersonal intelligence, their organizational citizenship behaviors are more susceptible to general just-world belief. These employees display problem-solving ability and effective communication skills. They can predict and solve the problems in social interpersonal relationships, exactly understand and predict whether others are treated fairly or not, and are aware of the needs of others. Therefore, they are more willing to offer assistance, which increases the chances of demonstrating organizational citizenship behaviors. Employees are the core force of enterprise development and the key to obtaining competitive advantages. Belief in a just world and interpersonal intelligence can help to improve employees' organizational citizenship behaviors and promote the effective operation and sustainable development of organizations.

\section{Conclusions}

This paper presents some major findings on the relationship between belief in a just world, organizational citizenship behaviors, and interpersonal intelligence. A significant positive correlation was found between belief in a just world and organizational citizenship behaviors, as well as a positive correlation between interpersonal intelligence and organizational citizenship behaviors. These findings highlight the importance of belief in a just world and interpersonal intelligence in enterprise development and further enhance our understanding of employees' organizational citizenship behaviors. According to the regression analysis, we further found that the predictive effect of just-world belief on organizational citizenship behaviors was influenced by interpersonal intelligence. The level of interpersonal intelligence had a significant impact on employees' organizational citizenship behaviors.

According to the findings of this study, corporate executives should first pay attention to the promotion effect of employees' just-world beliefs on organizational citizenship behaviors. They need to focus on the cultivation of belief in a just world in the training process; develop employees' belief in a just world; and encourage employees' voluntary extra-role behaviors by creating a fair, harmonious, and win-win organizational cultural atmosphere. Second, top executives should fully use interpersonal intelligence to enhance the effectiveness of the belief in a just world. When 
training employees, enterprises should also emphasize the cultivation and development of interpersonal intelligence and improve employees' ability to communicate and collaborate to create a harmonious enterprise environment to stimulate employees to devote themselves to the organization. In the Chinese workplace, which has a high power distance index, interpersonal intelligence and organizational citizenship behaviors have become two of the necessary political skills for employees. To improve their development, enterprises should not only emphasize the training and development of employees' technical skills but also highlight the development of employees' interpersonal intelligence, their belief in a just world, and other abilities and beliefs.

There are some limitations to this study. First, we adopted a self-reporting method to conduct a questionnaire survey, which causes common method biases. Second, since we used cross-sectional survey data, the influence of just-world belief and interpersonal intelligence on organizational citizenship behaviors may lead to a certain time hysteresis effect. For this reason, a follow-up study should adopt a longitudinal research design to collect research data to overcome such limitations.

Author Contributions: Liangli Han and Houyu Zhou contributed almost equally to designing this study and writing the manuscript. Liangli Han and Chunjie Wang performed the data processing and statistical analysis. Houyu Zhou revised the paper. All authors read and approved the final manuscript.

Funding: This research received no external funding

Institutional Review Board Statement: The study was conducted according to the guidelines of the Declaration of Helsinki and approved by the Academic Ethics Committee of Jinghengyi School of Education, Hangzhou Normal University.

Informed Consent Statement: Informed consent was obtained from all subjects involved in the study.

Data Availability Statement: The data presented in this study are available upon request from the corresponding author.

Acknowledgments: The authors thank Tingting Fu for collecting the data. Many thanks to all the peer reviewers for their excellent suggestions that contributed to improving this work.

Conflicts of Interest: The authors declare no conflict of interest.

\section{References}

1. Organ, \& Dennis, W. Organizational citizenship behavior: it's construct clean-up time. Human Performance. 1997,10(2), 85-97.

2. Smith, C. A.; Organ, D. W.; \& Near, J. P. Organizational citizenship behavior: its nature and antecedents. Journal of Applied Psychology. 1983, 68(4), 653-663.

3. Bies, R. J.; Organ, D. W. Organizational Citizenship Behavior:The Good Soldier Syndrome. The Academy of Management Review. 1989, 14(2):294.

4. Tansky, J. W. Justice and organizational citizenship behavior: what is the relationship? Employee Responsibilities and Rights Journal. 1993, 6(3), 195-207.

5. Eskew, D.E.'The role of organizational justice in organizational citizenship behavior'.Employee Responsibilities and Rights Journal. 1993, 6, 185-194.

6. Walz, S. M.; \& Niehoff, B. P. Organizational citizenship behaviors: their relationship to organizational effectiveness. Journal of Hospitality and Tourism Research. 2000, 24, 301e319.

7. Podsakoff, P. M.; Ahearne, M.; \& Mackenzie, S. B. Organizational citizenship behavior and the quantity and quality of work group performance. Journal of Applied Psychology. 1997, 82(2), 262-70.

8. Konovsky, M. A.; \& Organ, D. W. Dispositional and contextual determinants of organizational citizenship behavior. Journal of Organizational Behavior. 1996, 17, 253e266.

9. George, \& Jennifer, M. State or trait: effects of positive mood on prosocial behaviors at work. Journal of Applied Psychology. 1991, 76(2), 299-307.

10. Adams, J. S. Inequity in social exchange. Advances in Experimental Social Psychology. 1965, 2(4), 267-299.

11. Cropanzano, R.; \& Greenberg, J. Progress in Organizational Justice: Tunnelling Through the Maze. International Review of Industrial and Organizational Psychology. 1997, 12, 317-372.

12. Leventhal, G. S. The distribution of rewards and resources in groups and organizations - sciencedirect. Advances in Experimental Social Psychology. 1976, 9, 91-131. 
13. Ramamoorthy, N.; \& Flood, P.C. Gender and employee attitudes: the role of organizational justice perceptions. British Journal of Management. 2004, 15(3), 247-258.

14. Lerner, M. J.; \& Miller, D. T. Just world research and the attribution process: Looking back and ahead. Psychological Bulletin. 1978, 85(5):1030-1051.

15. Rubin, Z.; and Pcplan, L. A. Belief in a just world and reaction to another's lot: A study of participants in the national draft lottery. Journal of Social Issues. 1973, 29(4), 73-93.

16. Rubin, Z.; \& Peplau, L. A. Who believes in a just world? Journal of Social Issues. 2010, 31(3), 65-89.

17. Dalbert, C. The world is more just for me than generally: about the personal belief in a just world scale's validity. Social Justice Research. 1999, 12(2), 79-98.

18. Taylor, S. E.; \& Brown, J. D. Illusion and well-being: a social psychological perspective on mental health. Psychological Bulletin. 1988, 103(2), 193-210.

19. Zuckerman, \& Miron. Belief in a just world and altruistic behavior. Journal of Personality E Social Psychology. 1975, 31(5), 972-976.

20. DePalma, M. T.; Madey, S. F.; Tillman, T. C.; \& Wheeler, J. Perceived patient responsibility and belief in a just world affects helping. Basic and Applied Social Psychology. 1999, 21, 131-137.

21. Otto, K.; \& Schmidt, S. Dealing with stress in the workplace: compensatory effects of belief in a just world. European Psychologist. 2007, 12(4), 272-282.

22. Laurin, K.; Fitzsimons, G. M.; \& Kay, A. C. Social disadvantage and the self-regulatory function of justice beliefs. J Pers Soc Psychol. 2011, 100(1), 149-171.

23. Farh, J. L. Accounting for organizational citizenship behavior: leader fairness and task scope versus satisfaction. Journal of Management. 1990, 16(4), 705-721.

24. Moorman, R. H.; Organ, D. W.; \& Niehoff, B. P. Do fairness perceptions influence employee citizenship? A report of two studies on the relationship between three dimensions of organizational justice and organizational citizenship behavior. Paper presented at the annual meeting of the Academy of Management. 1991, Miami Beach.

25. Konovsky, M. A.; \& Pugh, S. D.Citizenship Behavior and Social Exchange. The Academy of Management Journal. 1994, 37(3), 656-669.

26. Moorman, R. H. Relationship between organizational justice and organizational citizenship behaviors: do fairness perceptions influence employee citizenship? Journal of Applied Psychology. 1991, 76(6), 845-855.

27. Niehoff, B. P.; \& Moorman, R. H. Justice as a mediator of the relationship between methods of monitoring and organizational citizenship behavior. Academy of Management Journal. 1993, 36(3), 527-556.

28. Lerner, M. J.; Miller, D .T . Just world research and the attribution process: Looking back and ahead. Psychological Bulletin. 1978, 85(5):1030-1051.

29. Mahmud, N.; Amaliyah, A. R.; Amin, N.; Jufri, M.; \& Alimuddin. The development of learning devices based on interpersonal intelligence to improve prospective teachers' social competence. Journal of Physics Conference Series. 2019, 1321, 022096.

30. Gardner, H. Frames of mind: the theory of multiple intelligences. Quarterly Review of Biology. 1985, 4(3), 19-35.

31. Mustapha Hajebi,SeddiQ Taheri,Mahdi Noshadi. The Relationship between Interpersonal Intelligence, Reading Activity and Vocabulary Learning among Iranian EFL Learners. International Journal of English Language and Translation Studies. 2018, 6(1): 48-56.

32. Fitri, Ayu, Kusumaningrum. Interpersonal intelligence and prosocial behavior among elementary school students. Management Science Letters. 2019, 9(10):1645-1654.

33. Cirelli, L. K. How interpersonal synchrony facilitates early prosocial behavior. Current Opinion in Psychology. $2018,20,35$.

34. Chen, X.; Hui, C.; \& Sego, D. The role of organizational citizenship behavior in turnover: conceptualization and preliminary tests of key hypotheses. Journal of Applied Psychology. 1993, 83(6), 922-931.

35. Lerner, M. J. The justice motive: some hypotheses as to its origins and forms. Journal of Personality. 2010, 45(1), 1-32.

36. Su, Z.; Zhang, D.; \& Wang, X. Revising of belief in a just world scale and its reliability and validity in college students.Chinese Journal of Behavioral Medicine and Brain Science. 2012, 21(6), 561-563.

37. Dalbert, C. The world is more just for me than generally: about the personal belief in a just world scale's validity. Social Justice Research. 1999, 12(2), 79-98.

38. Podsakoff, P. M.; Ahearne, M.; \& Mackenzie, S. B. Organizational citizenship behavior and the quantity and quality of work group performance. Journal of Applied Psychology. 1997, 82(2), 262-70.

39. Lu, J. Research on guanxi management of superior subordinate, psychological ownership and positive organizational behavior: based on non-family members of family business. (Doctoral dissertation, Guangdong University of Technology). 2015.

40. Caroli, M.; \& Sagone, E. Belief in a just world, prosocial behavior, and moral disengagement in adolescence. Procedia - Social and Behavioral Sciences. 2014, 116(116), 596-600.

41. Miller, D. T. Altruism and threat to a belief in a just world. Journal of Experimental Social Psychology. 1997, 13(2), 113-124.

42. Bègue, L.; Charmoillaux, M.; Cochet, J; Cury, C.; \& Suremain, F. D. Altruistic behavior and the bidimensional just world belief. American Journal of Psychology. 2008, 121(1), 47-56.

43. Teng, H.; Yao, J.; Li, Y.; \& Du, Z. A Study on the Influence of Beliefs in a Just World and Pro-social Behaviors on Juvenile Delinquency. Juvenile Delinquency Prevention Research. 2018, 000(002), 18-24.

44. Farwell, L.; \& Weiner, B. Self-perception of fairness in individual and group contexts. Pers.Soc. Psychol. Bull. 1996, $22,868-881$. 
45. Cirelli, L. K.; Einarson, K. M.; \& Trainor, L. J. Interpersonal synchrony increases prosocial behavior in infants. Developmental Science. 2014, 17(6).

46. Cirelli, L. K.; Wan, S. J.; \& Trainor, L. J. Fourteen-month-old infants use interpersonal synchrony as a cue to direct helpfulness. Philos Trans R Soc Lond B Biol. 2014, 369(20130400).

47. Hampson, \& Robert, B. Adolescent prosocial behavior: peer-group and situational factors associated with helping. Journal of Personality and Social Psychology. 1984, 46(1), 153-162.

48. Wentzel, K. R.; \& Mcnamara, C. C. Interpersonal relationships, emotional distress, and prosocial behavior in middle school. The Journal of Early Adolescence. 1999, 19(1), 114-125.

49. Markiewicz, D.; Doyle, A. B., \& Brendgen, M. The quality of adolescents' friendships: associations with mothers' interpersonal relationships, attachments to parents and friends, and prosocial behaviors. Journal of Adolescence. 2001, 24(4), 429-445.

50. Cialdini, R. B.; Kenrick, D. T.; \& Baumann, D. J. Effects of mood on prosocial behavior in children and adults. The Development of Prosocial Behavior. 1982, 339-359. 